\title{
동양행정론
}

\section{Ching(周易) Approach to Public Administration}

\author{
권일찬 \\ 충북대학교 행정학과
}

II-Chan Kwon(kilchan@chungbuk.ac.kr)

\section{요약}

본 고에서는 동양학의 학문적 체계를 살펴보고, 현대행정에 도움이 되는 개념과 이론 및 사상을 고찰하 여 동양행정론의 주요한 연구주제를 발굴하여 동양행정이 어떤 의미와 가치가 있는지를 고찰해 보고자 한 다. 동양행정 이란 첫째, 동양학적 개념과 이론 및 사상에 입각하여 행정현상과 문제를 이해 설명 해결하며, 둘째, 동양학적 관점에서 정책을 개발하는 학문을 의미한다. 동양학의 모든 학문적 근원은 주역(周易)이다. 주역에서 비롯된 동양학의 학문적 영역은 크게 분류하면 상수역(象數易)과 의리역(義理易)이 있다. 즉 상 수역에는 동양五術(命·ト·相·醫·山)과 천문기상 등이 있고, 의리역에는 유가, 도가, 묵가, 제자백가, 그 리고 성리학 등이 있다. 현대사회에서 동양행정론의 의미와 가치는 서양행정학과 상호보완하고 문제점과 한계점을 상호극복하며 새로운 시각에서 문제를 인식하고 해결할 수 있는 새롭고 앞선 부문이 있다는 점이다.

a 중심어 : | 동양행정 | 주역 | 상수역 | 기(氣) | 음양오행론 |

\section{Abstract}

The purpose of this article is to study on the public administration in the perspective of I Ching(周易) which is the original philosophy and science of East Asia. I Ching is divided into two different schools, namely, the school of Image- Number I(象數易) and the school of Right Theory I(義理易). The school of Image- Number I are five science and technology(名・卜・醫・ 相 -山) and astronomy, and so forth. And the school of Right Theory I are a Confucanist, a Taoist, a Mukist and all other thoughts. The meaning of Eastern Public Administration in mordern society is newer and better advanced concept, theory, and thoughts than western science and technology.

- keyword : | Eastern Public Administration | | Ching | Image-Number I | Chi | Yin Yang and Five Element |

\section{I. 서론}

본 고에서는 동양학의 학문적 체계를 살펴보고, 현 대행정에 도움이 되는 개념과 이론 및 사상을 고찰하여 동양행정론의 주요한 연구주제를 살펴보고자 한다. 그 리고 지금과 같이 서구화되고 근대화 된 사회에서, 동
양행정론이 어떤 의미와 가치가 있는지를 살펴보고자 한다.

동양의 역사를 볼 때 수 천년의 역사가 있어 왔으며, 이는 동서양을 막론하고 국가가 탄생한 이래로 정치와 행정 현상이 있어 왔다는 점에서, 동양에서도 당연히 정치와 행정 현상이 있어 왔다. 그리고 그러한 정치 행

\footnotetext{
* 이 논문은 2011학년도 충북대학교 학술연구지원사업의 연구비 지원에 의하여 연구되었음.

접수번호 : \#120224-004

심사완료일 : 2012년 03월 26일

접수일자 : 2012년 02월 24일

교신저자 : 권일찬, e-mail : kilchan@chungbuk.ac.kr
} 
정현상의 배경이 되는 학문인 동양학이 있다.

그렇다면 동양에서는 어떻게 정치와 행정을 행하여 왔는지를 이해하려면 어떠한 학문적 배경을 갖고서 정 치와 행정을 하였는가를 고찰해 보아야 한다. 즉 동양 의 고유한 행정과 정치현상을 이해하고 설명하며 해결 하기 위한 학문이 어떠한 것이 있었는가를 고찰하여야 지나간 동양의 정치 행정현상을 근본적으로 이해할 수 있다. 그것이 곧 동양학이다. 동양학 중에서도 모든 동 양학의 근원적 학문인 주역(周易)이 가장 중요한 학문 이다

그러므로 동양학, 특히 주역을 모르고 동양의 문화와 생활 및 역사를 연구하게 되면 근본적인 연구가 되지 않고 아무리해도 피상적인 연구밖에 될 수 없다. 그러 므로 우리의 생활과 문화 및 역사의 정체성을 근본적으 로 연구하기 위해서는 주역이 선택과목이 아니고 필수 과목이다.

뿐만 아니라 현대 행정과 정치 및 사회현상을 연구하 는데 새로운 것을 찾아보고자 하는 사람들에게 의미가 있고 가치가 있다. 즉 지적 호기심 내지는 새로운 것에 대한 추구와 탐구정신의 일환으로 동양학이 의미가 있다. 그렇다고 동양학을 하는데 모든 것을 하자는 것은 결 코 아니다. 왜냐하면 지금과 같이 세계화 개방화 열린 사고의 시대에 우리 것인 동양학을 하자고 해서, 우리 것이기 때문에 무조건 해야 한다는 것은 결코 바람직하 지 않다. 우리 것을 하되 지금 지배적인 위치에 있는 서 양과학과 비교해서 서양과학의 문제점과 한계점을 보 완하고 극복할 수 있으며 또한 새롭고 앞선 것을 해야 의미가 있고 가치가 있으며 생명력이 있다. 그러한 학 문이, 동양학 중에서도, 지금 제도권에서 배척을 당하고 있는 주역에서 비롯된 동양과학기술인 역학과 역술이다.

\section{II. 동양행정의 개념}

본 고에서 동양행정론 이라고 하면 첫째, 동양학적 개념과 이론 및 사상에 입각하여 행정현상과 문제를 이 해 설명 해결하며, 둘째, 동양학적 관점에서 정책을 개 발하는 학문을 의미한다. 그리고 서양과학과 비교해서
상호보완하고 문제점과 한계점을 극복하며 새로운 시 각에서 문제를 인식할 수 있는 새롭고 앞선 부문에 해 당되는 것을 의미한다.

현대 우리나라의 행정은 공식적인 관점에서 볼 때 서 양행정학이고 특히 미국행정학이라고 해도 과언이 아 니다. 즉 서양과학, 보다 구체적으로 말하면, 서양행정 학적 관점과 시각 그리고 개념과 이론에 의하여 서술하 며 이해 설명하고 문제를 해결하고 또한 정책을 개발한 다고 볼 수 있다.

그리고 미국행정학과 다소 다른 개념이라고 하면 한 국행정학이라는 개념이 있다. 한국행정학이란 서양과 학적 방법론과 서양행정학적 개념과 이론 사상에 입각 하여 한국 행정현상을 이해 설명하기 위한 행정학이라 고 볼 수 있다. 이런 점에서 볼 때 한국행정론도 사실상 넓은 의미의 서양행정학이라고 볼 수 있다. 왜냐하면 연구대상만 한국행정현상 이지 그 연구방법과 개념 이 론 사상도 거의 서양과학과 서양행정학의 개념과 이론 및 방법론에 입각하고 있기 때문이다.

이에 비해서 동양행정론은 행정 현상을 고찰하고 문 제를 해결하는 개념과 이론 및 사상이 다를 뿐만 아니 라 접근하는 방법론까지도 전혀 다른 학문이다. 즉 앞 에서 언급한 바와 같이 동양학적 개념과 이론 및 방법 론으로 행정 현상을 고찰하고 문제를 해결하는 학문이다.

동양행정론의 또 다른 개념은 동양학적 정책 개발을 의미한다.

지금까지 우리나라의 국가기관에서 행한 국가적인 정책 개발은 물질세계에 관한 학문인 서양과학적 또는 서양 물질문명적 정책 개발이 주가 되어 왔다고 본다. 그래서 모든 대학과 연구소는, 국가의 이러한 정책에 맞추어, 서양 물질과학적 학문만 주로 연구하고 가르치 고 있다고 해도 과언이 아니다. 이러한 정책개발의 특 징은 한마디로 물질위주의 경제성과 편리성 및 인공적 인 미적 감각에 입각한 청책이라고 볼 수 있다.

그러나 이에 비례해서 문제점과 부작용으로, 환경파 괴와 인간성이 상실되었음은 부인 할 수 없다. 그 동안 괄목할 만한 경제발전과 정치발전으로, 물질적으로 풍 요롭고 편리해 졌으며, 또한 제도적으로도 자유롭고 편 리해 졌다. 그러나 이에 비해서 지나친 개발과 정치사 
회의 급격한 변화로 자연환경 파괴와 인간성이 상실되 었다. 이에 따라서 정신적으로는 황폐화되고 공허해졌 으며, 극심한 사회변화와 치열해진 경쟁으로 불안 초조 감이 증가됨으로 인해서, 이를 복원하고, 충족 시켜주 고, 해소시켜줄 수 있는 정신세계의 지적수요가 국민들 사이에 새롭게 대두되고 있다.

동양학적 정책개발이란, 인간존중과 자연환경 친화 적이며 주로 의식을 성장시키기 위한 정신세계와 관련 이 깊은 정책을 의미 한다1. 이는 물질세계 위주의 지나 친 서양 과학물질 문명적 발달로 나타난 환경파괴와 인 간성 상실 문제를 보완하고 극복하며 대체시키기 위한 정책 개발이라고 볼 수 있다.

\section{III. 동양학의 학문적 체계}

동양학의 대가들의 일관된 말이 동양학의 근원적 학 문이 주역(周易)이다. 즉 동양의 모든 사상 철학뿐만 아 니라 과학기술도 주역에서 비롯되었다[1]. 따라서 동양 학이 주역이고 주역이 동양학이다.

동양학의 학문적 체계를 구체적으로 서술하면 다음 과 같다.

먼저 동양학의 전체적인 학문을 서양학의 학문적 영 역과 관련하여 크게 분류해 보면 철학, 기초학, 응용학 분야로 나눠 볼 수 있다. 이들의 내용을 보다 구체적으 로 기술하면 다음과 같다..

먼저 동양철학에 해당하는 우주의 가장 기본적인 실 체적 개념으로 기(氣) - 기(器) - 신의 개념이 있다. 그 리고 기(氣)의 작용과 변화 원리에 해당하는 법칙적이 고 이론적인 것으로는 도(道)와 리(理)가 있다. 이들의 관계를 살펴보면 먼저 氣의 작용과 변화원리에 의해 물

1 예를 들면 정신수련을 위한 각종 수련법, 도시 및 지역을 개발할 때 풍수지리의 이치에 맞게 개발하는 것, 유교 문화적이고 동양학적 관 광자원 개발, 氣의 과학 기술개발, 현대 서양과학으로 이해되지 않는 모든 국민들의 생활 속의 문제들을 해결하는데 도움을 주는 각종 민 간요법이나 역학 역술개발, 그리고 동양학의 질적 수준을 높이기 위 한 연구와 교육을 위한 정책적 지원 등이 있다. 동양학의 질적 수준 을 높이기 위한 정책에는 예를 들면 동양과학대학과 동양과학기술원 을 국가적인 차원에서 설립하여, 정책적으로 지원하여 동양과학기 술을 현대 과학적으로 연구하고 가르쳐 널리 보급하는 사업을 의미 한다.
질화 형상화 된 것을 사물인 기(⿳⼝⼝ㅁ라고 한다. 여기에서 형상화된 기(器)란, 첫째, 氣의 작용과 변화원리에 의하 여 물질화된 것을 의미하고, 둘째, 객관적으로 파악이 가능한 자연적 사회적 현상을 의미한다. 신과 기(氣)의 관계는 신이라는 실체도 기(氣)의 실체로 이뤄졌으나 기(氣)의 작용과 변화원리인 도와 리로 표현이 불가능 한 묘한 변화를 신의 작용과 변화원리라고 볼 수 있다.

이상 동양학의 기본개념인 기(氣) · 신·기(器) · 도 · 리의 개념간의 관계를 살펴보았으며 동양학은 몇 안돼는 개념으로 우주삼라만상에 관한 학문인 철학 과 학을 일관되게 기술하고 설명하고 있는 것이 특징이다.

동양학의 기초학에 관련된 기(氣)의 작용과 변화원리 로 나타난 구체적인 리적(理的)이고 도적(道的)인 우주 삼라만상의 변화 원리와 작용의 구체적인 내용을 설명 하면 다음과 같다.

먼저 무극(無極)과 태극(太極)이다. 무극이란 이 우주 가 탄생하기 이전 단계로써 오직 하나의 기(氣)로써의 상태만 존재하였던 상황을 의미한다. 태극이란 무극의 일기가 음양으로 분화하기 시작 단계를 의미한다. 지금 의 우주삼라만상은 무극 태극 상태로부터 수 없는 세월 동안 기(氣)가 분화하고 작용 변화하여 나타난 현상이 다. 그러므로 거꾸로 수 없는 세월을 거슬러 올라가면 현재의 수 없는 우주삼라만상은 무극 일기(一氣)만 존 재했던 상황이라고 추측할 수 있다.

하나의 기(氣)의 상태로 존재했던 무극이 분화하기 시작하면서 태극의 맑고 가벼운 기(氣)는 하늘(天; 양) 이 되었고 무겁고 탁한 기(氣)는 땅(星: 음))이 되었다. 그리고 하늘의 양의 기와 땅의 음의 기가 상호 작용하 여 인(人)이 나타났다. 여기에 인에 대한 개념은 단순히 사람만을 의미하는 것이 아니라 우주삼라만상과 만사 를 모두 포괄하여 나타낸 말이다. 즉 우주를 구성하는 모든 만물과 만사를 인으로 대표해서 나타낸 것이다. 그러므로 사람은 우주삼라만상 만사 중의 극히 일부분 에 지나지 않으며 다만 대표로써 人을 내세운 것에 지 나지 않는다. 이것을 소위 천지인(天地人) 삼재원리(三 才原理)이다.

삼재원리를 구성하고 있는 천지인 삼재간의 상호작 용과 삼재를 구성하고 있는 만사 만물들을 구체적으로 
분류하고 이들 분류한 개념 간의 상호작용을 나타낸 개 념과 이론으로, 음양론이 있고 음양으로부터 사상(四 象) 팔괘(八卦) 64卦로 분화한 이론체계가 있다. 그리고 오행론이 있다. 오행론에는 단순히 목화토금수 오행의 개념과 이들 간의 상호작용으로 나타낸 이론 체계가 있 고, 하늘과 땅의 순환원리를 나타낸 10 天干(五運) 12 地 支(六氣)의 오행론이 있다. 전자는 우주삼라 만상과 만 사를 오행으로 분류하고 이들 간의 관계를 상생(相生) 상극(相兛)의 상호관계로 이해 설명하는 이론체계이고, 후자는 우주순환원리에 의하여 하늘에는 10 천간 오행 의 기운이 순환하고 지구에는 12 지지 여섯 가지 기운이 순환하는 것을 전제로 이러한 순환이 만사만물에 상생 상극 관계로 어떠한 작용과 변화를 일으키는가를 설명 하는 이론체계이다.

위에서 기술한 기초학의 개념과 이론에 입각하여 실 용적 차원에서 도움을 줄 수 있는 응용학문인 상수역으 로 먼저 동양프術인 命 - 卜・相・醫・山學이 있다. 그 리고 천문기상 · 역법(曆法) · 병법 · 음률 · 서화등이 있 으며 끝으로 주자학인 성리학이 있다. 특히 동양오술은 인간의 일상생활의 문제들을 해결하고 극복하는데 실 제적으로 도움을 주는 피흉추길(避凶趨吉)의 목적으로 만들어진 전문 응용과학기술 분야이다.

이상의 동양학의 기초학의 개념과 이론들은 학문적 연원이 천부경(天符經) - 하도낙서(河圖 洛書) · 주역 (周易) · 홍범구주(洪範九疇)에서 비롯된 것이다2.

끝으로 지금까지 서술한 동양과학의 전반적인 분야 를 종합적으로 통합하여 상수역을 중심으로 체계화한 것을 간단히 표로 타내면 아래 [표 1]과 같다.

2 천부경은 상고시대부터 연유한 한국철학사상의 뿌리로써 주역의 이 치가 천부경의 이치와 아주 유사하고, 상고시대의 천부경과 주역의 사상은 결국 한 뿌리에서 나온 것이다 라고 볼 수 있다[2]. 河圖는 우주의 운행을 흰 점 25 개와 검은 점 30 개로 표현한 도본으로 이를 보고서 천지창조와 만물생성의 이치를 깨달아 복희씨가 처음으로 周 易 八卦를 그렸으며, 陰陽과 五行의 작용 등 만물생성의 이치를 담고 있다[3]. 洛書는 낙수에 나타난 신령스런 거북이의 등에 45 개의 점으 로 된 무늬가 있었는데, 夏禹氏는 이 무늬에서 五行이 서로 상극하며 조절하는 작용을 깨우쳐 9년 동안의 홍수를 다스릴 수 있었다고 전 한다. 洪範九疇는 禹王이 만든 9 가지 政治大法으로 周易과는 표리관 계에 있다. 그래서 洪範이 정치학이라면 周易은 우주학이요, 홍범이 五行學說이라면 주역은 除陽學說이다[4].

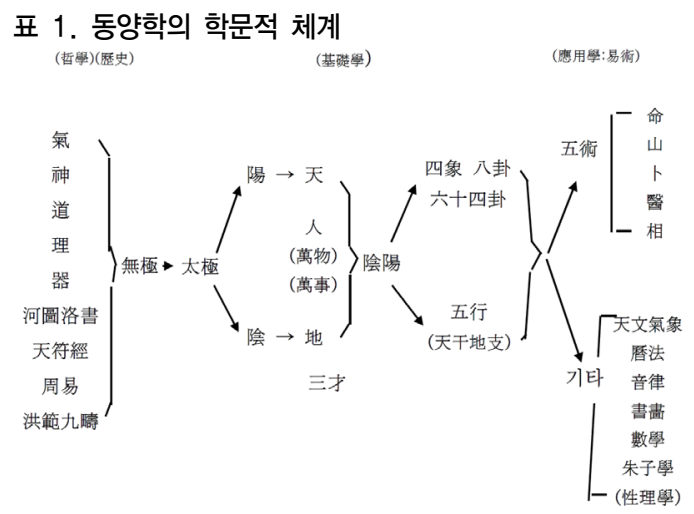

\section{IV. 동양행정론의 주요 주제}

III장에서 동양학에 대한 학문적 체계에 입각하여, 동 양행정론의 개념을 이해하는 데 도움을 주기 위해 현대 행정에서 의미 있고 가치가 있다고 생각되는 구체적인 주제와 문제는 다양하게 많으나 몇 가지만 선택하여 예 시하고자 한다. 여기서 제시한 주제들은 앞으로 동양행 정론에 관련된다고 생각되는 구체적인 주제를, 간단한 설명으로 예시한 것에 지나지 않는다. 앞으로 동양행정 론의 학문적 발전을 위해 보다 체계적으로 심도 있게 연구해야할 주제들이다.

\section{1. 동양학적 인간관}

사회과학은 인간사회에 대한 과학이다. 그러므로 사 회현상을 이해하는데 가장 기본적인 출발점은 인간에 대한 이해부터이다. 지금까지 사회과학에서 인간에 대 한 이해는 주로 서양과학적 인간관에 의해서만 이해 설 명해 왔다. 그러나 동양에서도 서양과학적 인간관과 전 혀 다른 새로운 시각의 다양한 인간모형이 있다.

동양학의 인간관에 대한 학설에는 동양의학적 인간 관, 성리학적 인간관, 명리학적 인간관, 상학적 인간모 형, 그리고 수행적 인간관이 있다. 동양의학적 인간모형 에는 오행인과 사상체질 등이 있다. 성리학은 천도에 입각한 인간의 도리에 대한 규범적인 인간관이다. 명리 학적 인간 모형은 인간 생활의 길흉화복에 관련된 학문 이다. 상학적 인간모형에는 면상-수상학 등이 있다. 
수행적 인간관은 궁극적 깨달음에 도달하기 위한 정신 수련적 인간모형이다.

\section{2. 동양학적 의사결정론}

동양학에서는 주요한 국가적인 의사결정 문제뿐만 아니라 개인적인 문제해결에 있어서 주역 점술에 의해 서 행하였다. 원래 주역은 위정자의 학문으로서 국가 통치를 위한 학문이고 그 중에 통치술의 하나가 주역점 이다. 그래서 국가의 주요한 대사는 주역점에 의해서 판단했다는 것이다.

점술은 미신도 아니고 비과학적인 것도 아니고, 인간 의 지혜를 다해도 판단이 안될 때 마지막으로 하늘과 신에게 물어보기 위한 체계화된 학문이며, 또한 서양과 학의 인과원리와 다른 동시성[同時性(synchronicity)] 이론에 의학 과학이다[5].

그리고 국가적인 청책결정에 있어서 정책의 운(運)도 고찰해서 판단을 해야한다. 정책의 운이란 우주론적 순 환론적 자연의 이치에 입각해 볼 때, 그 정책이 우주론 적 시간대에 적절한 가를 알아보는 구체적인 학문을 말 한다. 운에 관련해서는 개인의 운뿐만 아니라 국가 조 직 및 모든 것에는 운의 문제가 있다. 만사는 모두 다 때가 있다. 그 때에 대에 체계화한 학문이 오운육기(五 運六氣)이론이며 보다 구체적으로는 六十甲子이다.

\section{3. 동양학적 변화 발전론}

동양학에서는 모든 변화 발전론의 기본이론으로서 주역의 음양론과 홍범(洪範)의 오행론이 있으며, 주역 의 서괘전의 변화 발전이론과 택화혁괘(澤火革卦)의 이 론이 있다. 그리고 우주론적 순환원리에 입각한 후천개 벽 사상이 있으며, 소강절 선생의 황극경세론(皇極經世 論)에서는 지구의 운명에 대한 예측내용이 있다. 역학 역술에서도 우리나라를 비롯한 모든 나라의 미래를 예 측하는 국가관 세계관 우주관이 있다.

\section{4. 풍수지리적 명당(明롤행정론}

행정현상도 하늘과 땅 사이의 공간에서 일어나는 현 상이므로 하늘의 기운과 땅의 기운의 영향을 벗어날
수 없으며 당연히 천기와 지기의 영향을 받으면서 행해 지고 있다. 그럼으로 행정의 발전과 행정업무의 효율화 를 위해서는 지기(地氣)의 학문인 풍수지리에 입각한 행정을 하여야한다.

풍수지리에 입각한 바람직한 행정이란 풍수지리적 명당에서 행정이 행해져야 한다는 것을 대 전제로 하고 있다. 즉 풍수지리적 명당이란 풍수지리적으로 바람직 한 기운이 있는 곳에서 행정업무를 하여야 한다.

현대 행정이론에 의해서 아무리 조직 인사 재무 정책 이 행해진다 해도 그러한 행정이 행해지는 공간이 명당 이 아니고 흉지라면 의도한 결과가 나오기가 어럽다. 오히려 현대행정이론에 다소 바람직하지 않게 되어 있 어도 흉지가 아니고 명당에서 행해진다면 보다 바람직 한 행정이 이뤄진다. 왜냐하면 우리조상들이 발전시킨 동양학은 보다 근본적인 학문이기 때문이다. 즉 근본적 인 것이 바람직하면 지엽적인 조직 인사 재무 정책과 같은 기적(器的)인 것이 다소 문제가 있어도 크게 염려 할 필요가 없다.

\section{5. 동양학적 행정관리(조직 인사)}

조직내의 관리에 있어서 조직의 업무 분담과 설계 및 인사관리 등에 있어서 동양학적 개념과 이론에 의해서 행하면 그 만큼 보다 합리적이고 효율적인 경우가 있을 것이다. 즉 음양오행론, 사상, 팔괘론 등에 입각하여 조 직을 관리 설계하고 인사 관리를 하면은 보다 바람직한 결과 가 있을 것으로 본다. 즉 서양과학적으로 해결할 수 없는 문제를 동양학적으로 이해 설명되므로 해서 동 양학적 해결 방안을 모색할 수 있다.

최근에 국내 월간지에 실린 기사에 ‘주역경영'이란 주 제가 있었다. 내용 즉은 많은 기업인들이 실제 회사 경 영에 역학을 접목하는 경우가 적지 않다는 것이다. 즉 역학적 관점에서 인재를 뽑고 관리하고, 투자하고, 재테 크를 해서 큰 성과를 보기도 한다는 것이다.

그리고 경영자들의 경영 리더쉽에서 새로운 유형이 대두되고 있다. 기존의 관리자의 리더쉽이 주로 물질세 계 관련된 관리 유형이라면, 정신세계의 지적수요가 대 두되고 있는 현대에는조직 구성원들의 정신세계의 욕 구를 충족시켜 줄 수 있는 새로운 리더쉽이 요구된다. 
그 중에 하나가 소위 정신적 리더쉽 또는 영적(靈的) 리 더쉽이라고 볼 수 있다.

\section{V. 결론}

지금까지 동양행정학의 개념과 의미 및 동양학의 학 문적 체계를 주역에서 비롯된 상수역인 역학 역술을 중 심으로 고찰하였으며, 이에 근거하여 현대행정에 의미 있다고 생각되는 주요 주제들을 추출하여 간단하게 예 시를 하였다.

동양학의 근원적 학문인 周易을 동양학의 대가들이 평하기를, 철학자가 보면 철학이요, 과학자가 보면 과학 이요, 종교가가 보면 종교요, 점술가가 보면 점술이라고 한다. 이는 주역이 종합학문이며 인간생활의 모든 것을 포괄하고 있음을 나타낸 것이다. 서양학문이 과학 - 철 학 - 종교를 서로 분리해서 해 놓은 것에 비하면 아주 대조적이다.

우리는 지금 제도권에서는 서양과학 중심의 학문적 독재의 시대에 살고 있다. 정치 독재가 나라를 망하게 하지만, 학문적 독재는 모든 국민들의 눈과 귀 사고를 편향되게 하여 온전치 못한 반쪽짜리 인간으로 만들고 있다. 행정학의 경우도 서양행정학적 독재체제에 의하 여 모든 행정학의 교육 연구가 행해지고 있다. 그래서 제도권의 교육정책이 국민을 절반의 사람으로 만들고 있다. 즉 서구적 사상과 학문으로 만 무장된 반쪽짜리 의 편향된 인간으로 만들고 있다.

역사적으로 볼 때 17 세기 이후 서양의 근대과학이 동 양에 전파되면서 19 세기까지에 일어난 일들에 초점을 맞춘 주장에 의하면, 동양에는 인도와 중국 등에 훌륭 한 과학전통이 있었는데도 불구하고 그것이 그대로 전 개될 수 있게 내버려두지 않았기 때문에 동양의 위대한 전통은 파괴되고 지금은 좋지 못한 서양과학이 지구를 지배하게 되었다는 것이다. 이런 결과를 가져온 것은 서양의 식민주의가 서양과학의 우월성을 지나치게 강 조했고, 또 동양의 지식층이 이에 눈먼 채 추종을 하였 던 때문이다[6].

지금 우리는 세계화 개방화 열린 사고의 지구촌 시대 에 살아가고 있다. 그래서 국경을 초월해서 서구적인
학문과 문명이 하루가 멀다고 엄청나게 쏟아져 들어오 고 있어서, 우리나라의 현재 세계화 개방화 열린 사고 란, 서양중심의 세계화 개방화 열린 사고의 시대이다. 그런데 이에 비해서 우리 것에 대해서는 아직도 폐쇄적 이고 닫혀있어서 제도권에서는 우리 것을 미신이고 비 과학이라고 전혀 인정하고 있지 않다. 참으로 안타깝게 생각한다.

서구적인 것들을 받아드리고 이를 연구하고 배우는 것은, 선진적인 것을 받아드려서 우리자신을 되돌아보 고 반성하고 개선하여 우리도 서구 선진국을 따라잡기 위한 진취적인 노력이다. 그러나 그렇다고 우리 것은 모두 버리고 서구적인 것은 무조건 받아드리는 것도 엄 청난 문제이다. 즉 서구적인 것도 우리 것에 비해서 앞 서고 바람직하며, 문화와 체질에 맞는가를 따져 주체적 으로 취사선택하는 현명한 판단이 중요하다. 따라서 동 양학 중에서 서구적인 것 보다 새롭고 앞선 것은 계승 발전시키는 학문적 노력이 현대사회 무엇보다 중요하다 자신의 커뮤니티에 대한 독자적인 인지방식이 없이 다른 사람들의 생각과 방식으로 자신의 커뮤니티에서 일어나는 현상을 인식하는 사회는 결국 다른 사람들의 사회를 위한 종속체와 기생체가 되고 만다. 이의 내용 은 서구적 개념과 이론에 의존해서 자신의 문화와 생활 을 설명해야 한다는 강박관념에 사로잡혀 있는 동양의 문화와 학문 연구자들에게 따끔한 일침을 가한 예라고 본다[7].

\section{참 고 문 헌}

[1] 高懷民, 정병석 역, 周易哲學의 理解, 서울: 문예출 판사, 1978.

[2] 김석진, 周易과 世界, 서울: 동신출판사, 1991.

[3] 김석진, 周易入聞, 서울: 대유학당, 1997.

[4] 김석진, 周易과 世界, 서울: 동신출판사, 1991.

[5] 이정용, 易의 神學, 서울: 대한기독교서회, 1998.

[6] 박성래, “동아시아 전통과학과 도교”, 도교와 과 학, 서울: 비봉출판사, 1990.

[7] 조용헌, 오백년 내력의 명문가 이야기, 서울: 도서 출판 푸른역사, 2003. 


\section{저 자 소 개}

권 일 찬(Il-Chan Kwon)

\section{정회원}

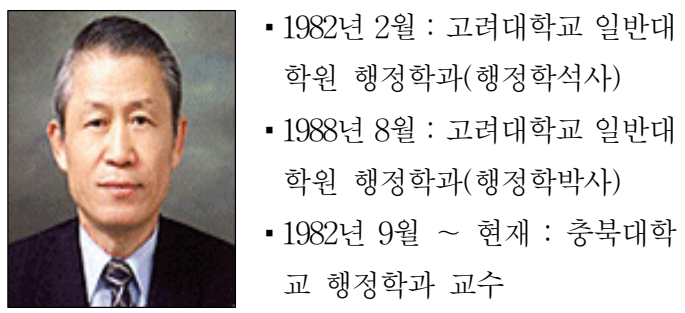

<관심분야> : 동양행정, 발전행정, 재무행정. 